\title{
The complete mitochondrial genome of Dysgonia stuposa (Lepidoptera: Erebidae) and phylogenetic relationships within Noctuoidea
}

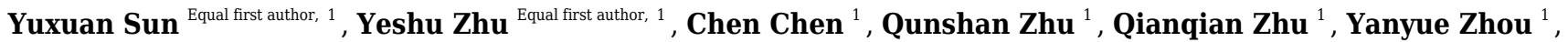 \\ Xiaojun Zhou ${ }^{1}$, Peijun Zhu ${ }^{1}$, Jun Li ${ }^{\text {Corresp., }}{ }^{1}$, HaiJun Zhang ${ }^{\text {Corresp. } 1}$ \\ ${ }^{1}$ College of Life Sciences, Huaibei Normal University, Huaibei, Anhui, China \\ Corresponding Authors: Jun Li, Haijun Zhang \\ Email address: healthlicn@chnu.edu.cn, haijunzhang@163.com
}

To determine the Dysgonia stuposa mitochondrial genome (mitogenome) structure and to clarify its phylogenetic position, the entire mitogenome of $D$. stuposa was sequenced and annotated. The $D$. stuposa mitogenome is $15,721 \mathrm{bp}$ in size and contains 37 genes (protein-coding genes, transfer RNA genes, ribosomal RNA genes) usually found in lepidopteran mitogenomes. The newly sequenced mitogenome contained some common features reported in other Erebidae species, e.g., an A+T biased nucleotide composition and a non-canonical start codon for coxl (CGA). Like other insect mitogenomes, the $D$. stuposa mitogenome had a conserved sequen ce 'ATACTAA' in an intergenic spacer between trnS2 and nad1, and a motif 'ATAGA' followed by a 20 bp poly-T stretch in the $A+T$ rich region. Phylogenetic analyses supported $D$. stuposa as part of the Erebidae family and reconfirmed the monophyly of the subfamilies Arctiinae, Catocalinae and Lymantriinae within Erebidae. 
1 The complete mitochondrial genome of Dysgonia stuposa (Lepidoptera: Erebidae) and

2

3 Yuxuan Sun*, Yeshu Zhu*, Chen, Chen, Qunshan Zhu, Qianqian Zhu, Yanyue Zhou, Xiaojun

4

5 (College of Life Sciences, Huaibei Normal University, Huaibei, Anhui, China)

6

7

8

9

10

11

12

\section{phylogenetic relationships within Noctuoidea}

Zhou, Peijun Zhu, Jun Li\#, HaiJun Zhang\#

6

7

8

*These two authors contributed equally to this work.

\section{\#Corresponding authors.}

Address: College of Life Sciences, Huaibei Normal University, 100 Dongshan Road, Huaibei,

Anhui, 235000 China.

Email: healthlicn@chnu.edu.cn (Jun Li), haijunzhang@163.com(HaiJun Zhang) 


\section{Abstract}

To determine the Dysgonia stuposa mitochondrial genome (mitogenome) structure and to clarify its phylogenetic position, the entire mitogenome of D. stuposa was sequenced and annotated. The D. stuposa mitogenome is $15,721 \mathrm{bp}$ in size and contains 37 genes (proteincoding genes, transfer RNA genes, ribosomal RNA genes) usually found in lepidopteran mitogenomes. The newly sequenced mitogenome contained some common features reported in other Erebidae species, e.g., an $\mathrm{A}+\mathrm{T}$ biased nucleotide composition and a non-canonical start codon for coxl (CGA). Like other insect mitogenomes, the D. stuposa mitogenome had a conserved sequence 'ATACTAA' in an intergenic spacer between $\operatorname{trnS} 2$ and nadl, and a motif 'ATAGA' followed by a 20 bp poly-T stretch in the A+T rich region. Phylogenetic analyses supported D. stuposa as part of the Erebidae family and reconfirmed the monophyly of the subfamilies Arctiinae, Catocalinae and Lymantriinae within Erebidae.

Keywords: Phylogenetic relationship; D. stuposa; Mitochondrial genome; Noctuoidea

\section{Introduction}

D. stuposa (Lepidoptera: Erebidae) is an important pest species, and it has a wide distribution throughout the southern and eastern parts of Asia. Its larvae mainly consume the leaves of Punica granatum (pomegranate) resulting in considerable economic losses. In the northern areas of China, D. stuposa pupates during the winter to avoid the harsh environment (Piao et al., 2012). The identification and prevention of D. stuposa at pupal stage based on morphological characteristics is quite difficult for taxonomists and population ecologists. Despite 
43 the economic importance, our understanding of D. stuposa biology or phylogenetic status at the

44 molecular level is still in its infancy. New molecular techniques such as DNA barcoding and

45 PCR-RFLP are considered more reliable than morphology for studying taxonomy of animals

46 (Arimoto \& Iwaizum, 2014; Raupach et al., 2010). The application of molecular techniques to

47 study the sequence of D. stuposa mitogenome will help in its precise identification and

48 classification while contributing to future genetic ecology and evolutionary analyses.

49 The insect mitogenome is typically a 14-19 kb sized, circular, double-stranded DNA

50 molecule (Boore, 1999). Compared to the nuclear genome, mitogenome is small in size and

51 comparatively easy to sequence. Mitogenome usually contains numerous typical characteristics,

52 such as stable gene composition, and conserved gene arrangements, which are widely used in

53 molecular identification, population genetics, systematics and biogeographic studies

54 (Wolstenholme, 1992; Wilson et al., 2010). Given the vast diversity of insects, mitogenome

55 analyses are beneficial for species identification and broadly employed in the study of genomic

56 evolution and phylogenetic relationships (Lu et al., 2013; Cameron, 2014).

57 Noctuoidea is one of the largest superfamilies of Lepidoptera, with over 42,400 described

58 species (Nieukerken et al., 2011). Unlike other superfamilies, a metathoracic tympanal organ is a

59 characteristic feature of Noctuoidea species (Miller, 1991). However, morphological based

60 phylogenetics has failed to resolve classification conflicts at the family and sub-family level.

61 Furthermore, the initial molecular studies were also unable to provide sufficient information as

62 most of them rely on one or two genes with only 29-49 species (Mitchell et al., 1997; Fang et al.,

63 2000). Mitchell et al. (2006) conducted systemic analyses based on two nuclear genes 
64 (elongation factor-1 $\alpha(E F-1 \alpha)$ and dopa decarboxylase $(D D C))$ and increased taxon sampling

65 (146 species), that supported the monophyly of sub-families and proposed a LAQ clade

66 (Lymantriidae and Arctiidae became subordinate subfamilies within quadrifid noctuids). Zahiri

67 et al. (2011) reconstructed the molecular phylogenetics of Noctuoidea using one mitochondrial

68 (coxl) and seven nuclear genes (EF-1 $\alpha$, wingless, RpS5, IDH, CMDH, GAPDH and CAD) from

69152 species with the Maximum Likelihood (ML) method. They proposed a new perspective, splitting up the traditional group of quadrifid noctuids, and re-establishing Erebidae and Nolidae

71 as families (Zahiri et al., 2011). However, this study failed to clarify phylogenetic relationships

72 between Erebidae subfamilies (Zahiri et al., 2012). Additionally, morphological studies were not entirely consistent with the molecular studies in challenging some traditional synapomorphies, such as the "quadrifid" forewing venation and the presence of a transverse sclerite in the pleural region of segment A1 (Minet et al., 2012).

Complete mitogenomes and the mitochondrial genes are increasingly applied to understand phylogenetic relationships. For example, Wang et al. (2015) proposed two new tribes and established relationships between them within Lymantriinae by using two mitochondrial genes (coxl and $r r n L)$ along with six nuclear genes, using ML and Bayesian Inference (BI). The nucleotide and amino acid sequences of mitochondrial PCGs are also broadly used to determine the taxonomic status of species and to analyze phylogenetic relationships within Erebidae (Yang \& Kong, 2016; Liu et al., 2017). Furthermore, as the mitogenome differs from the nuclear genome, it has been increasingly used to investigate poorly supported phylogenetic questions 
species of the genus Dysgonia have been moved to other genera, including Erebidae and Noctuidae based on the classification of Holloway and Miller (2003), the taxonomic status of many species remained uncertain. In our study, we sequenced the complete mitogenome of $D$. stuposa and reconstructed phylogenetic relationships to assess its phylogenetic position within Noctuoidea. The newly sequenced mitogenome supported new phylogenetic relationships within Erebidae and will provide a foundation for further studies into Noctuidae and Erebidae mitogenomics, biogeography, and phylogenetics.

\section{Materials and Methods}

\section{Specimen collection and Genomic DNA extraction}

The D. stuposa moths were collected from Xiangshan mountains (N33 $59^{\prime} 47^{\prime \prime}$, E116 $47^{\prime} 42^{\prime \prime}$ ), Huaibei, Anhui, China. Based on morphological characteristics, the collected specimens were identified as D. stuposa using the record in Fauna Sinica (Chen, 2003). The genomic DNA (contains nuclear genome and mitogenome) of D. stuposa was isolated using the Animal Genomic DNA Isolation Kit according to the manufacturer's instructions (Sangon, Shanghai, China).

\section{PCR amplification and fragment sequencing}

To amplify the D. stuposa mitogenome, the universal (F1-R13) and specific primers (S1FS3R) were used to perform PCR amplification (Table 1) (Sun et al., 2016). All PCR amplifications were executed using high fidelity DNA Polymerase (PrimeSTAR ${ }^{\circledR}$ GXL, Takara, Dalian, China). PCRs was performed according to Sun et al. (2016) with extension times depending on the putative length of target fragment. PCR product size was determined by 
106 107 108 109 110 directions and repeated three times.

\section{Sequence assembly and annotation} (Benson, 1999).

\section{Phylogenetic analysis}

agarose gel with TAE buffer, then sequenced at General Biosystems (General, Chuzhou, China) in both forward and reverse directions using ABI 3500 Genetic Analyzer by the Sanger sequencing method. For long fragments, internal sequencing primers were designed based on known fragment sequence. For the $\mathrm{A}+\mathrm{T}$ rich region, the fragment was sequenced from two

The complete mitogenome was assembled using the DNAMAN (https://www.lynnon.com/index.html). Sequence annotation (supplied in supplemental files) was performed by MITOS2 Web Server (http://mitos2.bioinf.uni-leipzig.de/index.py) and confirmed by BLAST to homologous sequences in NCBI (https://blast.ncbi.nlm.nih.gov/Blast.cgi). To determine PCG initiation and termination codons, sequences were aligned with other published Noctuoidea sequences using ClustalX 2.0 (Larkin et al., 2007). AT skew and GC skew values were calculated using the methods given by Perna \& Kocher (1995). MEGA 5.0 software was used to analyze relative synonymous codon usage (RSCU) (Tamura et al., 2011). tRNA genes were determined by tRNAscan Search Server (http://lowelab.ucsc.edu/tRNAscan-SE/) and secondary structures inferred from folding into their canonical clover-leaf structures (Lowe \& Eddy, 1997). rRNA genes were determined by MITOS2 Web Server and confirmed by BLAST with the homologous sequences in NCBI. Tandem Repeats Finder (http://tandem.bu.edu/trf/trf.html) was used to analyze non-coding regions for tandem repeats 

concatenated nucleotide sequence alignments for PCGs from 42 species (Table 2) was performed. (AY048187) and Antheraea pernyi (AY242996) (Liu et al., 2008) were used as outgroups.

partitioned and performed in IQ-TREE (http://iqtree.cibiv.univie.ac.at/) with the best-fit model sites were presented and performed with MrBayes 3.2.6 (Ronquist et al., 2012). One cold chain and three heated chains were run with the dataset for 10 million generations with the tree being sampled every 1000 generations. After discarding the first 25\% samples as burn-in, posterior probabilities were calculated. The phylogenetic trees were visualized in FigTree software (http://tree.bio.ed.ac.uk/software/figtree/).

\section{Results and Discussion}

\section{Genome organization and composition}

The D. stuposa mitogenome is a circular DNA molecule, which is $15,721 \mathrm{bp}$ in length

144 (accession number: MK262707) (Figure 1). The size of the newly sequenced mitogenome is comparable to other Noctuoidea species, which range from 15,377 bp (Agrotis ipsilon) to 15,801 bp (Gynaephora minora) (Table 3). The variation in size is generally due to differences in the 
148 Annotation found the typical 37 genes and a non-coding $\mathrm{A}+\mathrm{T}$ rich region like most of the 149 sequenced insect mitogenomes (Table 4). An A and $\mathrm{T}$ biased nucleotide composition is a 150 characteristic feature of insect mitogenomes (Boore, 1999), and D. stuposa is no exception.

151 Nucleotide composition of D. stuposa was highly biased towards using A and T $(\mathrm{A}=39.98 \%$, $152 \mathrm{~T}=40.38 \%, \mathrm{G}=7.5 \%, \mathrm{C}=12.14 \%$ ) (Table 3 ); $80.36 \%$ total $\mathrm{A}+\mathrm{T}$ content is comparable to 153 previously sequenced lepidopterans (ranges from $77.84 \%$ in Ochrogaster lunifer to $81.49 \%$ in 154 Gynaephora minora).

156 (Perna and Kocher, 1995); with negative AT skew (-0.005) and GC skew (-0.236), indicating the 157 presence of more Ts than As, and Cs than Gs, respectively (Table 3). Negative AT skew has been reported in several other insect species such as Asota plana lacteata (-0.002), Risoba prominens (-0.007) and Agrotis ipsilon (-0.006).

\section{Protein-coding genes and codon usage}

PCGs identified from the D. stuposa mitogenome had a total length of 11,269 bp, accounting for $71.7 \%$ of the mitogenome. In insects, most PCGs are on the $\mathrm{J}$ strand (majority), while some of them reside on the N strand (minority) (Simon et al., 1994). In D. stuposa, nine of the thirteen PCGs (nad2, cox1, cox2, atp8, atp6, cox3, nad3, nad6 and cob) are encoded on the Jstrand, while the remaining PCGs (nad5, nad4, nad4L and nad1) are on the N-strand. An ATN codon initiated all PCGs except coxl, which uses a CGA codon, as in most Lepidoptera (Table

(Liu et al., 2014; Dai et al., 2016). 
To estimate codon usage among Noctuoidea species and to assess similarities and variations

in codon usage and distribution, PCGs nucleotide sequences of seven Noctuoidea (belonging to

four families: Erebidae, Noctuidae, Nolidae and Notodontidae) were compared (Figure 2). In $D$.

and isoleucine (Ile) were the most commonly used amino acids, while cysteine (Cys) was the

most rarely utilized amino acid. Codon usage is similar across Noctuoidea. Furthermore, we used

the codons per thousand (CDspT) metric to illustrate the codons distribution in different species

(Dai et al., 2015) (Figure 3). CDspT results exhibited similar trends across the Noctuoidea superfamily, with the maximum CDspT value observed for Asn and Ile.

Relative Synonymous Codon Usage (RSCU) for Noctuoidea species is presented in Figure

4. Codons usage within a given amino acid varied between species. All codons were found in $D$.

stuposa, except ACG and CCG. Some noctuid species lack GC rich synonymous codons, with G

or $\mathrm{C}$ at the third codon position, such as GCG, CGC, GGC and CCG (e.g., these are not present

in A. ipsilon) (Wu et al., 2015). The rarity or complete absence of GC-rich codons occur in

various insect species (Yu et al., 2017; Li et al., 2018).

184

185

186

187

188

189

\section{Ribosomal RNA and transfer RNA genes}

The D. stuposa mitogenome contains the large $(r r n L)$ and small ribosomal genes (rrnS), encoded by the $\mathrm{N}$ strand with a length of 1,308 bp and $782 \mathrm{bp}$, respectively (Figure 1, Table 4). In D. stuposa, $r r n L$ was located between $\operatorname{trnL} 1$ and $\operatorname{trn} V$, while $r r n S$ was resided between $\operatorname{trn} V$ and the AT-rich region, as reported in previously sequenced mitogenomes (Yang et al., 2009).

There are 22 tRNA genes in the D. stuposa mitogenome, ranging in size from $57 \mathrm{bp}($ trnA) 
190

191

192

193

194

195

196

197

198

199

200

201

202

203

204

205

206

207

208

209

210

to $71 \mathrm{bp}(\operatorname{trnK})$ (Table 4). Almost all tRNAs had the canonical clover-leaf secondary structure, except trnS1 that lacks the dihydrouridine (DHU) arm (Figure 5), a common feature of trnS1 across mitogenomes of insects (Lavrov et al., 2000; Zhang et al., 2013). Stem pair mismatches in the secondary structure of tRNAs were observed such as an A-A mismatch (trnM), U-G mismatches (trn $I, \operatorname{trn} Q, \operatorname{trn} W, \operatorname{trn} Y, \operatorname{trn} L 2, \operatorname{trn} G, \operatorname{trn} F, \operatorname{trn} H, \operatorname{trn} T, \operatorname{trn} P, \operatorname{trn} V), \mathrm{U}-\mathrm{U}$ mismatches $(\operatorname{trn} Y, \operatorname{trn} L 2, \operatorname{trnS2})$ and a U-C mismatch $(\operatorname{trn} A)$. These mismatches may be corrected by an RNA-editing process which was proposed by Lavrov et al. (2000), but has not been investigated fully in Lepidoptera.

\section{Overlapping, intergenic spacer and $\mathrm{A}+\mathrm{T}$ rich regions}

Overlapping genes has been proposed to extend the genetic information possibly within the limited size of the genome, and are commonly observed in metazoan mitogenomes (Wolstenholme, 1992). We identified nine overlapping regions, a total length of 144 bp (Table 4). A seven bp overlapping region present at the boundary of atp 6 and atp 8 has also been reported in many other insects. The D. stuposa mitogenome also had 21 intergenic spacer regions, ranging in size from 1 to $105 \mathrm{bp}$. The $105 \mathrm{bp}$ spacer located between $\operatorname{trn} A$ and $\operatorname{trnR}$ and had high $\mathrm{A}$ and $\mathrm{T}$ content $(\mathrm{A}=47.62 \%$ and $\mathrm{T}=49.52 \%)$ and a similar spacer has been described in Andraca theae (77 bp spacer with $\mathrm{A}=46.75 \%$ and $\mathrm{T}=44.16 \%$ ). We also observed a 22 bp spacer that contained an 'ATACTAA' motif located between nadl and trnS2 (Figure 6A). This region commonly exists in most insect mitogenomes even though the region varies in size between lepidopteran species (Cameron \& Whiting, 2008).

Metazoan mitogenomes usually have a single large non-coding region, named as the $\mathrm{A}+\mathrm{T}$ 
211 rich region (Clayton, 1991). It contains initiation signals for DNA transcription and replication

212 (Fernández-Silva et al., 2003). The A+T rich region of D. stuposa mitogenome is located

213 between $r r n S$ and $\operatorname{trnM}$ and is $406 \mathrm{bp}$ in size (Table 4), with the negative GC skew (-0.355) and

214 highest $\mathrm{A}+\mathrm{T}$ content (92.37\%) of the genome (Table 3). The $\mathrm{A}+\mathrm{T}$ rich region usually contains

215 multiple tandem repeat elements (Zhang \& Hewitt, 1997); however, D. stuposa did not have

216 macro-repeats but does include short repeating sequences. It has the 'ATAGA' motif along with

217 a 20 bp poly-T repeat, a microsatellite-like (AT) $)_{10}$ repeat and a poly-A repeat sequence upstream

218 of $\operatorname{trnM}$ (Figure 6B). The poly-T stretch varies between different species (Dai et al., 2015), but

219 the 'ATAGA' motif is conserved in insects (Zhang \& Hewitt, 1997).

220

221

222

223

224

225

226

227

228

229

230

231

\section{Phylogenetic relationships}

To determine the phylogenetic position of D. stuposa, we reconstructed phylogenetic relationships with Noctuoidea species. In phylogenetic analyses, mitogenome PCGs have a lower sensitivity to analytical bias compared to other genes such as the tRNA or rRNA genes (Yang et al., 2015). Here, we applied the nucleotide sequence of the 13 PCGs for phylogenetic analyses using BI and ML methods. Results showed that D. stuposa is closely related to Grammodes geometrica, a clade that was well supported by both the methods (Figure 7A and 7B). D. stuposa belongs to the family Erebidae and subfamily Catocalinae, consistent with the reported classification of Erebidae (Zahiri et al., 2011). Erebidae is a large noctuid family (Yang et al., 2015); however, its monophyly remained unconfirmed, especially for Catocalinae (Zahiri et al., 2012). In the present study, the Catocalinae was found monophyletic, but nodal support values were not significant, i.e. 0.76 posterior probability (BI) and $31 \%$ bootstrap values (ML). There is 
232 still some controversy about relationships of Catocalinae under Erebidae. Zahiri et al. (2011)

233 demoted Catocalinae to a tribe Catocalini within the subfamily Erebinae, and upgraded Anobini

234 (formerly as a tribe within Catocalinae by Holloway, (2005)) to subfamily Anobinae. Several

235 species of the Dysgonia genus have been reclassified into Noctuidae (Holloway \& Miller, 2003),

236 results in further complications for phylogenetic analysis. Within Erebidae, our study supported

237 the monophyly of subfamilies and suggested that Catocalinae is a subfamily, most closely related

238 to Hypeninae (BI) or Aganainae (ML) (Figure 7A and 7B). Furthermore, Noctuoidea contained

239 four families: Notodontidae, Erebidae, Nolidae and Noctuidae, for which their phylogenetic

240 relationship was Notodontidae $+($ Erebidae $+($ Nolidae + Noctuidae $))$ with strong nodal support

241 in both ML and BI trees. Since there is limited data of complete mitogenome sequences from

242 Oenosandridae and Euteliidae in the public repository NCBI, our results are consistent with the

243 previous family-level phylogenetic hypothesis proposed by Zahiri et al. (2011).

\section{Reference}

245 Arimoto M, Iwaizum R. 2014. Identification of Japanese Lymantria species (Lepidoptera:

246 Lymantriidae) based on PCR-RFLP analysis of mitochondrial DNA. Applied Entomology $247 \quad$ and Zoology 49:159-169.

248 Benson G. 1999. Tandem repeats finder: a program to analyze DNA sequences. Nucleic Acids $249 \quad$ Research 27:573-580.

250 Boore JL. 1999. Animal mitochondrial genomes. Nucleic Acids Research 27:1767-1780.

251 Cameron SL. 2014. Insect Mitochondrial Genomics: Implications for Evolution and Phylogeny. 
253 Cameron SL, Whiting MF. 2008. The complete mitochondrial genome of the tobacco hornworm, 254 Manduca sexta (Insecta: Lepidoptera: Sphingidae) and an examination of mitochondrial gene variability within butterflies and moths. Gene 408:0-123.

256

257

258

259

260

261

262

263

264

265

266

267

268

269

270

271

272

273

Chen YX. 2003. Fauna Sinica: Vol. 16. Insecta, Lepidoptera, Noctuidae (Chinese Edition). Beijing: Science Press, 2-3.

Clayton DA. 1991. Replication and Transcription of Vertebrate Mitochondrial DNA. Annual Review of Cell Biology 17:453-478.

Dai LS, Qian C, Zhang CF, Wang L, Wei GQ, Li J, Zhu BJ, Liu CL, Ling EJ. 2015. Characterization of the Complete Mitochondrial Genome of Cerura menciana and Comparison with Other Lepidopteran Insects. PLoS ONE 10:e132951.

Dai LS, Zhu BJ, Qian C, Zhang CF, Li J, Wang L, Wei GQ, Liu CL. 2016. The complete mitochondrial genome of the diamondback moth, Plutella xylostella (Lepidoptera: Plutellidae). Mitochondrial DNA. Part A 27:1512-1513.

Fang QQ, Mitchell A, Regier JC, Mitter C, Friedlander TP, Poole RW. 2000. Phylogenetic utility of the nuclear gene dopa decarboxylase in Noctuid moths (Insecta: Lepidoptera: Noctuoidea). Molecular Phylogenetics and Evolution 15:473-486.

Fernández-Silva P, Enriquez JA, Montoya J. 2003. Replication and transcription of mammalian mitochondrial DNA. Experimental Physiology 88:41-55.

Holloway JD. 2005. The Moths of Borneo (part 15 \& 16): family Noctuidae, subfamily Catocalinae. Malayan Nature Journal 58:1-529.

Holloway JD, Miller SE. 2003. The composition, generic placement and host-plant relationships 
of the joviana-group in the Parallelia generic complex (Lepidoptera: Noctuidae, Catocalinae). Invertebrate Systematics 17:111-128.

Larkin MA, Blackshields G, Brown NP, Chenna R, Mcgettigan PA, Mcwilliam H, Lopez R. 2007. Clustal W and Clustal X version 2.0. Bioinformatics 23:2947-2948.

Lavrov DV, Brown WM, Boore JL. 2000. A novel type of RNA editing occurs in the mitochondrial tRNAs of the centipede Lithobius forficatus. Proceedings of the National Academy of Sciences 97:13738-13742.

Li J, Zhang YY, Hu KJ, Zhao YQ, Lin RR, Li Y, Huang ZR, Zhang X, Geng XX, Ding JH. 2018. Mitochondrial genome characteristics of two Sphingidae insects (Psilogramma increta and Macroglossum stellatarum) and implications for their phylogeny. International Journal of Biological Macromolecules: S0141813018304422.

Liu QN, Zhu BJ, Dai LS, Wang L, Qian C, Wei GQ, Liu CL. 2014. The complete mitochondrial genome of the common cutworm, Spodoptera litura (Lepidoptera: Noctuidade). Mitochondrial DNA :1-2.

Liu Y, Li Y, Pan M, Dai F, Zhu X, Lu C, Xiang Z. 2008. The complete mitochondrial genome of the Chinese oak silkmoth, Antheraea pernyi (Lepidoptera: Saturniidae). Acta Biochimica et Biophysica Sinica 40:693-703.

Liu Y, Xin ZZ, Zhu XY, Zhao XM, Wang Y, Tang BP, Zhang HB, Zhang DZ, Zhou CL, Liu QN. 2017. The complete mitochondrial genome of Euproctis similis (Lepidoptera: Noctuoidea: Erebidae) and phylogenetic analysis. International Journal of Biological Macromolecules:S0141813017311339. 
295 Lowe TM, Eddy SR. 1997. tRNAscan-SE: A Program for Improved Detection of Transfer RNA

296 Genes in Genomic Sequence. Nucleic Acids Research 25:955-964.

297 Lu HF, Su TJ, Luo AR, Zhu CD, Wu CS. 2013. Characterization of the Complete Mitochondrion

298 Genome of Diurnal Moth Amata emma (Butler) (Lepidoptera: Erebidae) and Its

299 Phylogenetic Implications. PLoS ONE 8:e72410.

300 Lv C, Li Q, Kong L. 2018. Comparative analyses of the complete mitochondrial genomes of

301 Dosinia clams and their phylogenetic position within Veneridae. PLoS ONE 13:e0196466.

302 Miller JS. 1991. Cladistics and classification of the Notodontidae (Lepidoptera, Noctuoidea)

Minet J, Barbut J, Lalanne-Cassou B. 2012. Les Noctuelles: classification et clé de détermination

Mitchell A, Cho S, Regier JC, Mitter C, Poole RW, Matthews M. 1997. Phylogenetic utility of elongation factor-1 alpha in Noctuoidea (Insecta: Lepidoptera): the limits of synonymous substitution. Molecular Biology and Evolution 14:381-390.

Mitchell A, Mitter C, Regier JC. 2006. Systematics and evolution of the cutworm moths (Lepidoptera: Noctuidae): evidence from two protein-coding nuclear genes. Systematic Entomology 31:21-46.

Nieukerken E, Kaila L, Kitching I, Kristensen NP, Lees DC. 2011. Order Lepidoptera Linnaeus, 1758. Zootaxa 3148:212-221.

Perna NT, Kocher TD. 1995. Patterns of nucleotide composition at fourfold degenerate sites of 
animal mitochondrial genomes. Journal of Molecular Evolution 41(3):353-358.

317 Piao MH, Fan LH, Zheng YC. 2012. Last Instar Larval Morphology of Three Species of

318 Catocalinae (Lepidoptera: Noctuidae) from China. vol. 134: Information Technology and 857-862.

Raupach MJ, Astrin JJ, Hannig K, Peters MK, Stoeckle MY, Wägele JW. 2010. Molecular species identification of Central European ground beetles (Coleoptera: Carabidae) using nuclear DNA expansion segments and DNA barcodes. Frontiers in Zoology 7:1-15.

324 Agricultural Engineering. Advances in Intelligent and Soft Computing. Berlin: Springer,

Ronquist F, Teslenko M, Van Der Mark P, Ayres DL, Darling A, Höhna S, Larget B, Liu L, Suchard MA, Huelsenbeck JP. 2012. MrBayes 3.2: efficient Bayesian phylogenetic inference and model choice across a large model space. Systems Biology 61:539-542.

Simon C, Frati F, Beckenbach A, Crespi B, Liu H, Flook P. 1994. Evolution, weighting, and phylogenetic utility of mitochondrial gene sequences and a compilation of conserved polymerase chain reaction primers. Annals of the Entomological Society of America 87:651701.

Sun Y, Chen C, Gao J, Abbas MN, Kausar S, Qian C, Wang L, Wei G, Zhu BJ, Liu CL. 2017. Comparative mitochondrial genome analysis of Daphnis nerii and other lepidopteran insects reveals conserved mitochondrial genome organization and phylogenetic relationships. PLoS ONE 12:e0178773.

Sun YX, Wang L, Wei GQ, Qian C, Dai LS, Sun Y, Abbas MN, Zhu BJ, Liu CL. 2016. Characterization of the Complete Mitochondrial Genome of Leucoma salicis (Lepidoptera: 
Tamura K, Peterson D, Peterson N, Stecher G, Nei M, Kumar S. 2011. MEGA5: Molecular

Evolutionary Genetics Analysis Using Maximum Likelihood, Evolutionary Distance, and Maximum Parsimony Methods. Molecular Biology and Evolution 28:2731-2739. (W1):W232-W235. 140.

Wang H, Wahlberg N, Holloway JD, Bergsten J, Fan XL, Janzen DH, Hallwachs W, Wen L, Wang M, Nylin S. 2015. Molecular phylogeny of Lymantriinae (Lepidoptera, Noctuoidea, Erebidae) inferred from eight gene regions. Cladistics :1-14.

Wilson AC, Cann RL, Carr SM, George M, Gyllensten UB, Helm-Bychowski KM, Higuchi RG, Palumbi SR. Prager EM, Sage RD, Stoneking M. 2010. Mitochondrial DNA and two perspectives on evolutionary genetics. Biological Journal of the Linnean Society 26:375400.

Wolstenholme DR. 1992. Animal mitochondrial DNA: structure and evolution. International Review of Cytology 141:173.

Wu QL, Cui WX, Wei SJ. 2015. Characterization of the complete mitochondrial genome of the black cutworm Agrotis ipsilon (Lepidoptera: Noctuidae). Mitochondrial DNA 26(1):139-

Yang J, Kong W. 2016. The complete mitochondrial genome of Lemyra melli (Daniel) (Lepidoptera, Erebidae) and a comparative analysis within the Noctuoidea. Zoological 
359

360

361

362

363

364

365

366

367

368

369

370

371

372

373

374

375

376

Yang L, Wei ZJ, Hong GY, Jang ST, Wen LP. 2009. The complete nucleotide sequence of the mitochondrial genome of Phthonandria atrilineata (Lepidoptera: Geometridae). Molecular Biology Reports 36:1441-1449.

Yang X, Cameron SL, Lees DC, Xue D, Han H. 2015. A mitochondrial genome phylogeny of owlet moths (Lepidoptera: Noctuoidea), and examination of the utility of mitochondrial genomes for lepidopteran phylogenetics. Molecular Phylogenetics and Evolution 85:230237.

Zahiri R, Holloway JD, Kitching IJ, Lafontaine JD, Mutanen M, Wahlberg N. 2012. Molecular phylogenetics of Erebidae (Lepidoptera, Noctuoidea). Systematic Entomology 37:102-124.

Zahiri R, Kitching IJ, Lafontaine JD, Mutanen M, Kaila L, Holloway JD, Wahlberg N. 2011. A new molecular phylogeny offers hope for a stable family level classification of the Noctuoidea (Lepidoptera). Zoologica Scripta 40:158-173.

Zhang DX, Hewitt GM. 1997. Insect mitochondrial control region: A review of its structure, evolution and usefulness in evolutionary studies. Biochemical Systematics and Ecology 25:99-120.

Zhang HL, Zeng HH, Huang Y, Zheng ZM. 2013. The complete mitochondrial genomes of three grasshoppers, Asiotmethis zacharjini, Filchnerella helanshanensis and Pseudotmethis rubimarginis (Orthoptera: Pamphagidae). Gene 517:89-98. 


\section{Table 1 (on next page)}

Details of the primers used to amplify the mitochondrial DNA of D. stuposa 
1 Table 1. Details of the primers used to amplify the mitochondrial DNA of D. stuposa

\begin{tabular}{|c|c|}
\hline Primer name & Nucleotide sequence $\left(5^{\prime}-3^{\prime}\right)$ \\
\hline F1 & TAAAAATAAGCTAAATTTAAGCTT \\
\hline $\mathrm{R} 1$ & TATTAAAATTGCAAATTTTAAGGA \\
\hline $\mathrm{F} 2$ & AAACTAATAATCTTCAAAATTAT \\
\hline $\mathrm{R} 2$ & AAAATAATTTGTTCTATTAAAG \\
\hline F3 & ATTCTATATTTCTTGAAATATTAT \\
\hline R3 & CATAAATTATAAATCTTAATCATA \\
\hline F4 & TGAAAATGATAAGTAATTTATTT \\
\hline $\mathrm{R} 4$ & AATATTAATGGAATTTAACCACTA \\
\hline F5 & TAAGCTGCTAACTTAATTTTTAGT \\
\hline R5 & CCTGTTTCAGCTTTAGTTCATTC \\
\hline F6 & CCTAATTGTCTTAAAGTAGATAA \\
\hline R6 & TGCTTATTCTTCTGTAGCTCATAT \\
\hline F7 & TAATGTATAATCTTCGTCTATGTAA \\
\hline R7 & ATCAATAATCTCCAAAATTATTAT \\
\hline F8 & ACTTTAAAAACTTCAAAGAAAAA \\
\hline R8 & TCATAATAAATTCCTCGTCCAATAT \\
\hline F9 & GTAAATTATGGTTGATTAATTCG \\
\hline R9 & TGATCTTCAAATTCTAATTATGC \\
\hline F10 & CCGAAACTAACTCTCTCTCACCT \\
\hline R10 & CTTACATGATCTGAGTTCAAACCG \\
\hline F11 & CGTTCTAATAAAGTTAAATAAGCA \\
\hline R11 & AATATGTACATATTGCCCGTCGCT \\
\hline F12 & TCTAGAAACACTTTCCAGTACCTC \\
\hline R12 & AATTTTAAATTATTAGGTGAAATT \\
\hline F13 & TAATAGGGTATCTAATCCTAGTT \\
\hline R13 & ACTTAATTTATCCTATCAGAATAA \\
\hline S1F & ACTTTAAAAACTTCAAAGAAAAA \\
\hline S1R & ACTTAATTTATCCTATCAGAATAA \\
\hline S2F & CGCAACTGCTGGCACAAA \\
\hline S2R & GAAGAGAAGTTTATAGTGGATGAGGTT \\
\hline S3F & TAAGCTGCTAACTTAATTTTTAGT \\
\hline S3R & $\begin{array}{l}\text { GTAATAAATTCCTCGTCCAATAT } \\
\text { GTACA }\end{array}$ \\
\hline
\end{tabular}

2 
Table 2 (on next page)

Details of the lepidopteran mitogenomes used in this study. 
1

Table 2. Details of the lepidopteran mitogenomes used in this study.

\begin{tabular}{|c|c|c|c|c|}
\hline Family & Subfamily & Species & Size (bp) & GenBank No \\
\hline \multirow[t]{22}{*}{ Erebidae } & Arctiinae & Spilarctia subcarnea & 15,441 & KT258909 \\
\hline & & Lemyra melli & 15,418 & KP307017 \\
\hline & & Hyphantria cunea & 15,481 & GU592049 \\
\hline & & Nyctemera arctata albofasciata & 15,432 & KM244681 \\
\hline & & Callimorpha dominula & 15,496 & KP973953 \\
\hline & & Aglaomorpha histrio & 15,472 & KY800518 \\
\hline & & Amata formosae & 15,463 & KC513737 \\
\hline & & Cyana sp. MT-2014 & 15,494 & KM244679 \\
\hline & & Paraona staudingeri & 15,427 & KY827330 \\
\hline & & Vamuna virilis & 15,417 & KJ364659 \\
\hline & Catocalinae & Grammodes geometrica & 15,728 & KY888135 \\
\hline & & Catocala sp. XY-2014 & 15,671 & KJ432280 \\
\hline & & Dysgonia stuposa & 15,721 & This study \\
\hline & Herminiinae & Hydrillodes lentalis & 15,570 & MH013484 \\
\hline & Aganainae & Asota plana lacteata & 15,416 & KJ173908 \\
\hline & Hypeninae & Paragabara curvicornuta & 15,532 & KT362742 \\
\hline & Lymantriinae & Gynaephora minora & 15,801 & KY688086 \\
\hline & & Gynaephora aureata & 15,773 & KJ507132 \\
\hline & & Lachana alpherakii & 15,755 & KJ957168 \\
\hline & & Gynaephora qumalaiensis & 15,753 & KJ507134 \\
\hline & & Euproctis similis & 15,437 & KT258910 \\
\hline & & Somena scintillans & 15,410 & MH051839 \\
\hline \multirow[t]{14}{*}{ Noctuidae } & Noctuinae & Agrotis ipsilon & 15,377 & KF163965 \\
\hline & & Agrotis segetum & 15,378 & KC894725 \\
\hline & Hadeninae & Mythimna separata & 15,329 & KM099034 \\
\hline & & Protegira songi & 15,410 & KY379907 \\
\hline & Amphipyrinae & Sesamia inferens & 15,413 & JN039362 \\
\hline & & Spodoptera exigua & 15,365 & JX316220 \\
\hline & & Spodoptera litura & 15,383 & KF701043 \\
\hline & & Spodoptera frugiperda & 15,365 & KM362176 \\
\hline & Heliothinae & Helicoverpa armigera & 15,347 & GU188273 \\
\hline & & Helicoverpa zea & 15,343 & KJ930516 \\
\hline & & Helicoverpa assulta & 15,400 & KT626655 \\
\hline & & Heliothis subflexa & 15,323 & KT598688 \\
\hline & Plusiinae & Ctenoplusia agnata & 15,261 & KC414791 \\
\hline & & Ctenoplusia limbirena & 15,306 & KM244665 \\
\hline \multirow[t]{2}{*}{ Nolide } & Chloephorinae & Gabala argentata & 15,337 & KJ410747 \\
\hline & Risobinae & Risoba prominens & 15,343 & KJ396197 \\
\hline
\end{tabular}




\begin{tabular}{|l|l|l|l|l|}
\hline Notodontidae & Thaumetopoeinae & Ochrogaster lunifer & 15,593 & AM946601 \\
\hline & Phalerinae & Phalera flavescens & 15,659 & JF440342 \\
\hline outgroup & & Bombyx mori & 15,664 & AY048187 \\
\hline outgroup & & Antheraea pernyi & 15,566 & AY242996 \\
\hline
\end{tabular}

2 
Table 3 (on next page)

Composition and skew in mitogenomes of Noctuoidea species. 
1 Table 3. Composition and skew in mitogenomes of Noctuoidea species.

$\begin{array}{lllllllll}\text { Species } & \text { Size (bp) } & \text { A } \% & \text { G } \% & \text { T\% } & \text { C } \% & \text { A }+\mathrm{T} \% & \text { AT skew } & \text { GC skew }\end{array}$

\begin{tabular}{ccccccccc}
\hline Whole genome & & & & & & & & \\
\hline D. stuposa & 15721 & 39.98 & 7.5 & 40.38 & 12.14 & 80.36 & -0.005 & -0.236 \\
A. plana lacteata & 15416 & 40.08 & 7.49 & 40.26 & 12.16 & 80.34 & -0.002 & -0.238 \\
V.a virilis & 15417 & 40.18 & 7.56 & 40.22 & 12.05 & 80.4 & 0.000 & -0.229 \\
G. minora & 15801 & 40.97 & 6.77 & 40.52 & 11.75 & 81.49 & 0.006 & -0.269 \\
R. prominens & 15343 & 40.25 & 7.8 & 40.82 & 11.13 & 81.07 & -0.007 & -0.176 \\
O. lunifer & 15593 & 40.09 & 7.56 & 37.75 & 14.6 & 77.84 & 0.030 & -0.318 \\
A. ipsilon & 15377 & 40.38 & 7.71 & 40.87 & 11.04 & 81.25 & -0.006 & -0.178 \\
\hline PCGs & & & & & & & & \\
\hline D. stuposa & 11269 & 33.80 & 10.91 & 44.64 & 10.65 & 78.45 & -0.138 & 0.012 \\
A. plana lacteata & 11211 & 33.87 & 10.92 & 44.76 & 10.45 & 78.63 & -0.138 & 0.022 \\
V. virilis & 11203 & 33.14 & 11.16 & 45.43 & 10.27 & 78.57 & -0.156 & 0.042 \\
G. minora & 11237 & 34.72 & 10.11 & 44.98 & 10.2 & 79.7 & -0.129 & -0.004 \\
R. prominens & 11216 & 33.64 & 10.57 & 46 & 9.8 & 79.64 & -0.155 & 0.038 \\
O. lunifer & 11266 & 32.47 & 12.08 & 43.26 & 12.19 & 75.73 & -0.142 & -0.005 \\
A. ipsilon & 11211 & 34.24 & 10.64 & 45.56 & 9.55 & 79.8 & -0.142 & 0.054 \\
\hline A+T rich & & & & & & & & \\
\hline D. stuposa & 406 & 43.6 & 2.46 & 48.77 & 5.17 & 92.37 & -0.056 & -0.355 \\
A. plana lacteata & 328 & 46.04 & 1.22 & 48.48 & 4.27 & 94.52 & -0.026 & -0.556 \\
V. virilis & 362 & 44.48 & 1.1 & 50.55 & 3.87 & 95.03 & -0.064 & -0.557 \\
G. minora & 449 & 43.21 & 2.67 & 49.44 & 4.68 & 92.65 & -0.067 & -0.273 \\
R. prominens & 342 & 44.15 & 2.34 & 49.42 & 4.09 & 93.57 & -0.056 & -0.272 \\
O. lunifer & 319 & 44.51 & 1.57 & 48.9 & 5.02 & 93.41 & -0.047 & -0.524 \\
A. ipsilon & 332 & 46.08 & 1.51 & 48.8 & 3.61 & 94.88 & -0.029 & -0.410 \\
\hline & & & & & & & & \\
\hline
\end{tabular}

2 
Table 4 (on next page)

List of annotated mitochondrial genes of $D$. stuposa 
1 Table 4. List of annotated mitochondrial genes of D. stuposa

\begin{tabular}{|c|c|c|c|c|c|c|c|c|}
\hline $\begin{array}{l}\text { Gene } \\
\text { name }\end{array}$ & Start & Stop & Strand & Length & $\begin{array}{l}\text { Anti- } \\
\text { codon }\end{array}$ & $\begin{array}{c}\text { Start } \\
\text { codon }\end{array}$ & $\begin{array}{c}\text { End } \\
\text { codon }\end{array}$ & $\begin{array}{l}\text { Intergenic } \\
\text { nucleotides }\end{array}$ \\
\hline $\operatorname{trn} M$ & 1 & 68 & $\mathrm{~J}$ & 68 & CAT & 1 & / & 2 \\
\hline $\operatorname{trn} I$ & 71 & 138 & $\mathrm{~J}$ & 68 & GAT & 1 & I & 8 \\
\hline $\operatorname{trn} Q$ & 147 & 215 & $\mathrm{~N}$ & 69 & TTG & I & I & 55 \\
\hline $\operatorname{nad} 2$ & 271 & 1284 & $\mathrm{~J}$ & 1014 & I & ATT & TAA & -2 \\
\hline $\operatorname{trn} W$ & 1283 & 1350 & $\mathrm{~J}$ & 68 & TCA & I & I & -8 \\
\hline $\operatorname{trn} C$ & 1343 & 1409 & $\mathrm{~N}$ & 67 & GCA & I & I & 22 \\
\hline $\operatorname{trn} Y$ & 1432 & 1496 & $\mathrm{~N}$ & 65 & GTA & 1 & I & 9 \\
\hline $\operatorname{cox} 1$ & 1506 & 3041 & $\mathrm{~J}$ & 1536 & I & CGA & TAA & -5 \\
\hline $\operatorname{trn} L 2$ & 3037 & 3103 & $\mathrm{~J}$ & 67 & TAA & I & 1 & 0 \\
\hline $\cos 2$ & 3104 & 3820 & $\mathrm{~J}$ & 717 & 1 & ATA & TAA & -35 \\
\hline $\operatorname{trn} K$ & 3786 & 3856 & $\mathrm{~J}$ & 71 & CTT & / & / & 0 \\
\hline $\operatorname{trn} D$ & 3857 & 3923 & $\mathrm{~J}$ & 67 & GTC & 1 & I & 0 \\
\hline atp 8 & 3924 & 4085 & $\mathrm{~J}$ & 162 & 1 & ATC & TAA & -7 \\
\hline atp6 & 4079 & 4756 & $\mathrm{~J}$ & 678 & 1 & ATG & TAA & 27 \\
\hline $\cos 3$ & 4784 & 5572 & $\mathrm{~J}$ & 789 & I & ATG & TAA & 2 \\
\hline $\operatorname{trn} G$ & 5575 & 5640 & $\mathrm{~J}$ & 66 & TCC & I & I & 0 \\
\hline nad3 & 5641 & 5994 & $\mathrm{~J}$ & 354 & I & ATT & TAA & 34 \\
\hline $\operatorname{trn} A$ & 6029 & 6085 & $\mathrm{~J}$ & 57 & TGC & 1 & I & 105 \\
\hline $\operatorname{trn} R$ & 6191 & 6256 & $\mathrm{~J}$ & 66 & TCG & 1 & 1 & 10 \\
\hline $\operatorname{trn} N$ & 6267 & 6332 & $\mathrm{~J}$ & 66 & GTT & I & I & 8 \\
\hline trnS1 & 6341 & 6406 & $\mathrm{~J}$ & 66 & GCT & 1 & I & 32 \\
\hline $\operatorname{trn} E$ & 6439 & 6506 & $\mathrm{~J}$ & 68 & TTC & 1 & 1 & 50 \\
\hline $\operatorname{trn} F$ & 6557 & 6624 & $\mathrm{~N}$ & 68 & GAA & 1 & / & -17 \\
\hline nad5 & 6608 & 8368 & $\mathrm{~N}$ & 1761 & 1 & ATT & TAA & -3 \\
\hline $\operatorname{trn} H$ & 8366 & 8433 & $\mathrm{~N}$ & 68 & GTG & 1 & 1 & 0 \\
\hline nad4 & 8434 & 9772 & $\mathrm{~N}$ & 1338 & 1 & ATG & TA & 42 \\
\hline nad4l & 9815 & 10102 & $\mathrm{~N}$ & 288 & 1 & ATG & TAA & 14 \\
\hline $\operatorname{trn} T$ & 10117 & 10181 & $\mathrm{~J}$ & 65 & TGT & 1 & 1 & 0 \\
\hline $\operatorname{trn} P$ & 10182 & 10246 & $\mathrm{~N}$ & 65 & TGG & 1 & I & 7 \\
\hline nad6 & 10254 & 10784 & $\mathrm{~J}$ & 531 & 1 & ATT & TAA & 14 \\
\hline$c o b$ & 10799 & 11959 & $\mathrm{~J}$ & 1161 & I & ATG & TAA & -2 \\
\hline $\operatorname{trnS2}$ & 11958 & 12025 & $\mathrm{~J}$ & 68 & TGA & 1 & 1 & 22 \\
\hline nadl & 12048 & 12986 & $\mathrm{~N}$ & 939 & I & ATG & TAA & 1 \\
\hline $\operatorname{trn} L 1$ & 12988 & 13055 & $\mathrm{~N}$ & 68 & TAG & I & I & 65 \\
\hline$r r n L$ & 13121 & 14428 & $\mathrm{~N}$ & 1308 & 1 & 1 & 1 & 37 \\
\hline $\operatorname{trn} V$ & 14466 & 14533 & $\mathrm{~N}$ & 68 & TAC & 1 & I & 0 \\
\hline$r r n S$ & 14534 & 15315 & $\mathrm{~N}$ & 782 & 1 & 1 & 1 & 0 \\
\hline AT-rich & 15316 & 15721 & I & 406 & 1 & 1 & 1 & 1 \\
\hline
\end{tabular}




\section{Figure 1}

Map of the mitogenome of $D$. stuposa.

tRNA genes are labeled according to the IUPAC-IUB one-letter amino acids; cox1, cox2 and cox3 refer to the cytochrome c oxidase subunits; cob refers to cytochrome b; nad1-nad6 refer to NADH dehydrogenase components. The moth was photographed by the corresponding author Jun Li. 


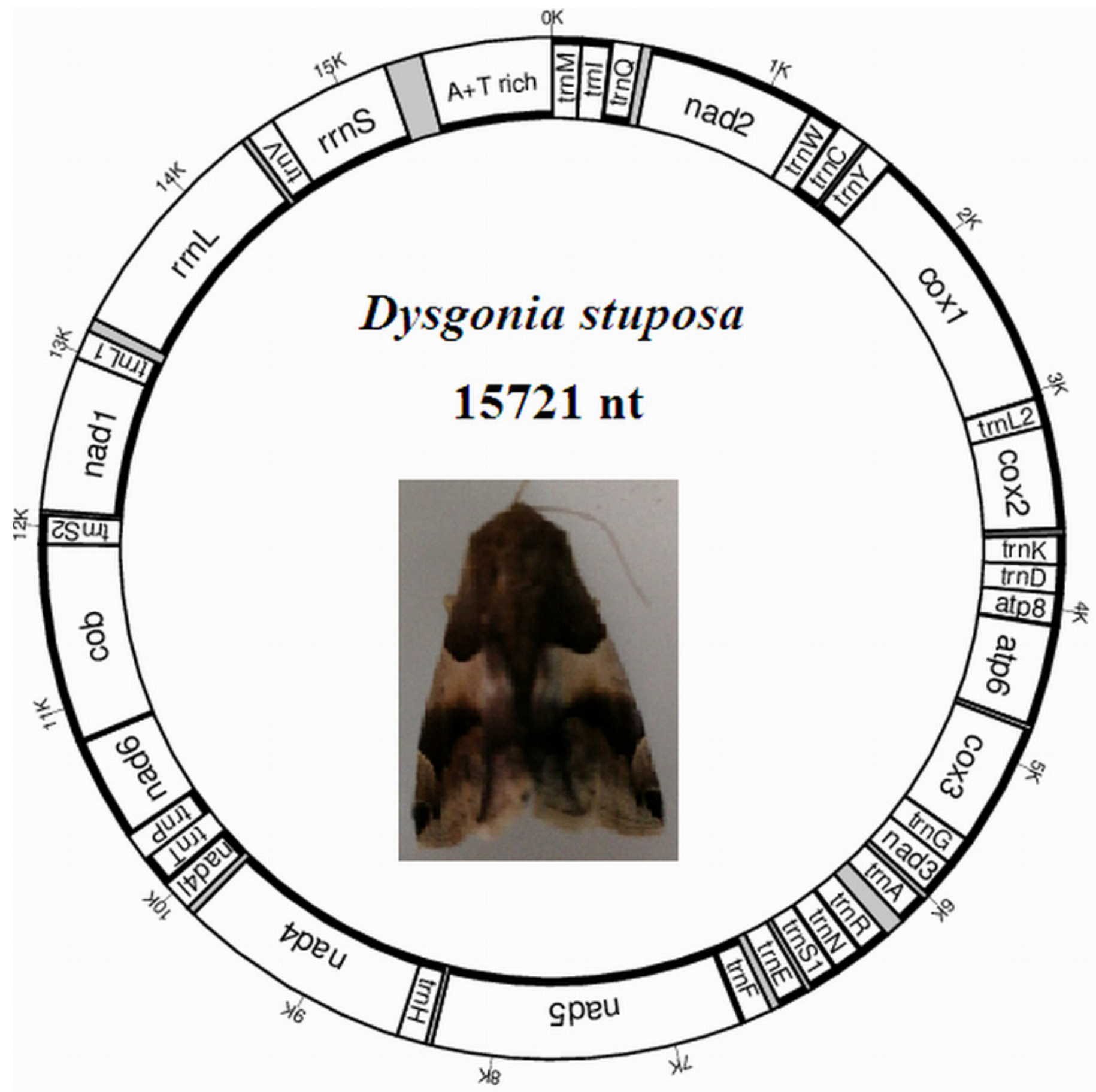




\section{Figure 2}

Comparison of codon usage within the mitochondrial genome of members of the Noctuoidea.

Lowercase letters ( $a, b, c$ and $d)$ above species names represent the family to which the species belongs (a: Erebidae, b: Nolide, c: Notodontidae, d: Noctuidae).

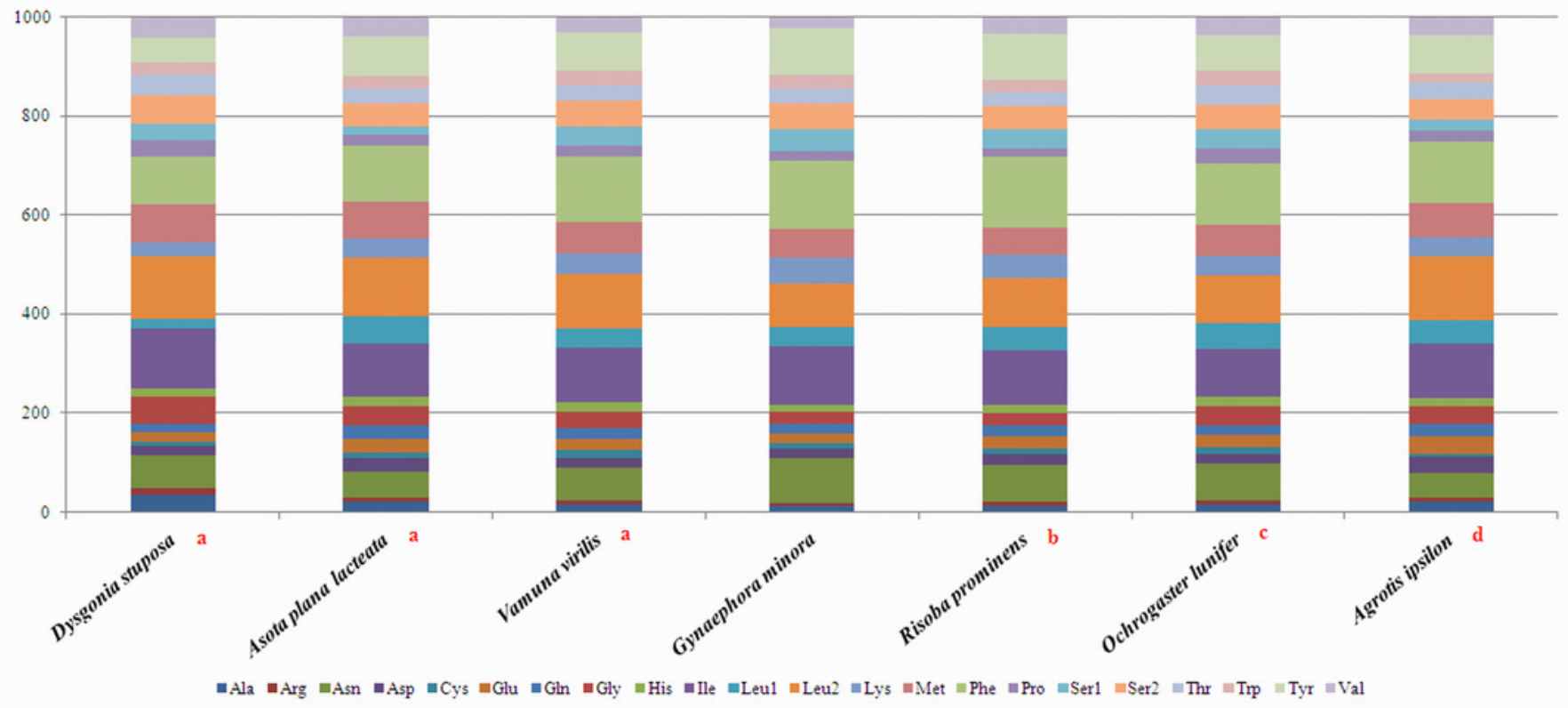


Figure 3

Codon distribution in members of the Noctuoidea.

CDsp $T=$ codons per thousand codons. 

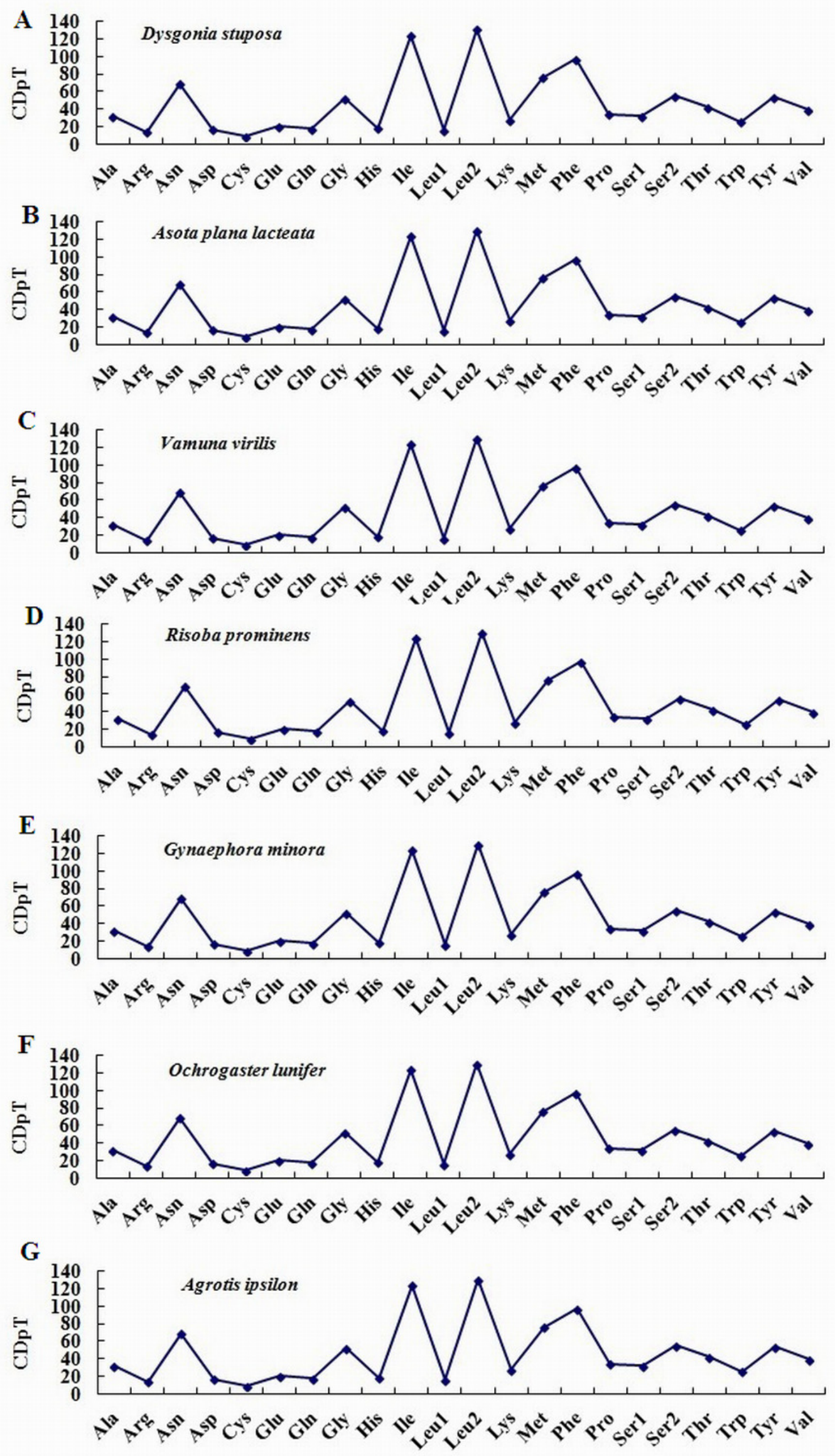
Figure 4

Relative Synonymous Codon Usage (RSCU) of the mitochondrial genome of four families in the Noctuoidea.

Codon families are plotted on the x-axis. Codons indicated above the bar are not present in the mitogenome. 

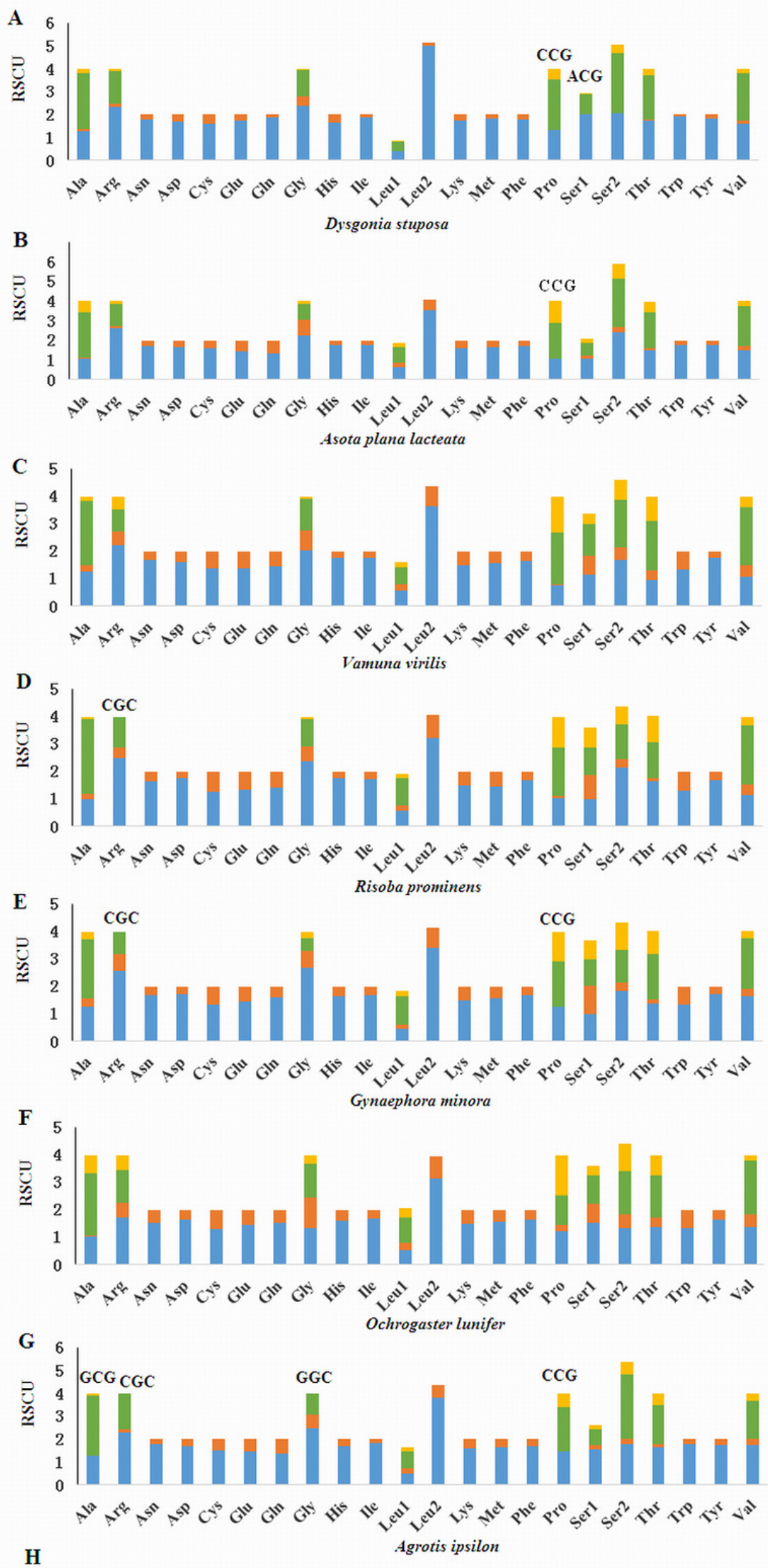

H

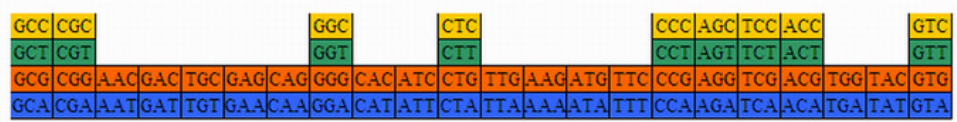


Figure 5

Predicted secondary structures of the 22 tRNA genes of the $D$. stuposa mitogenome. 


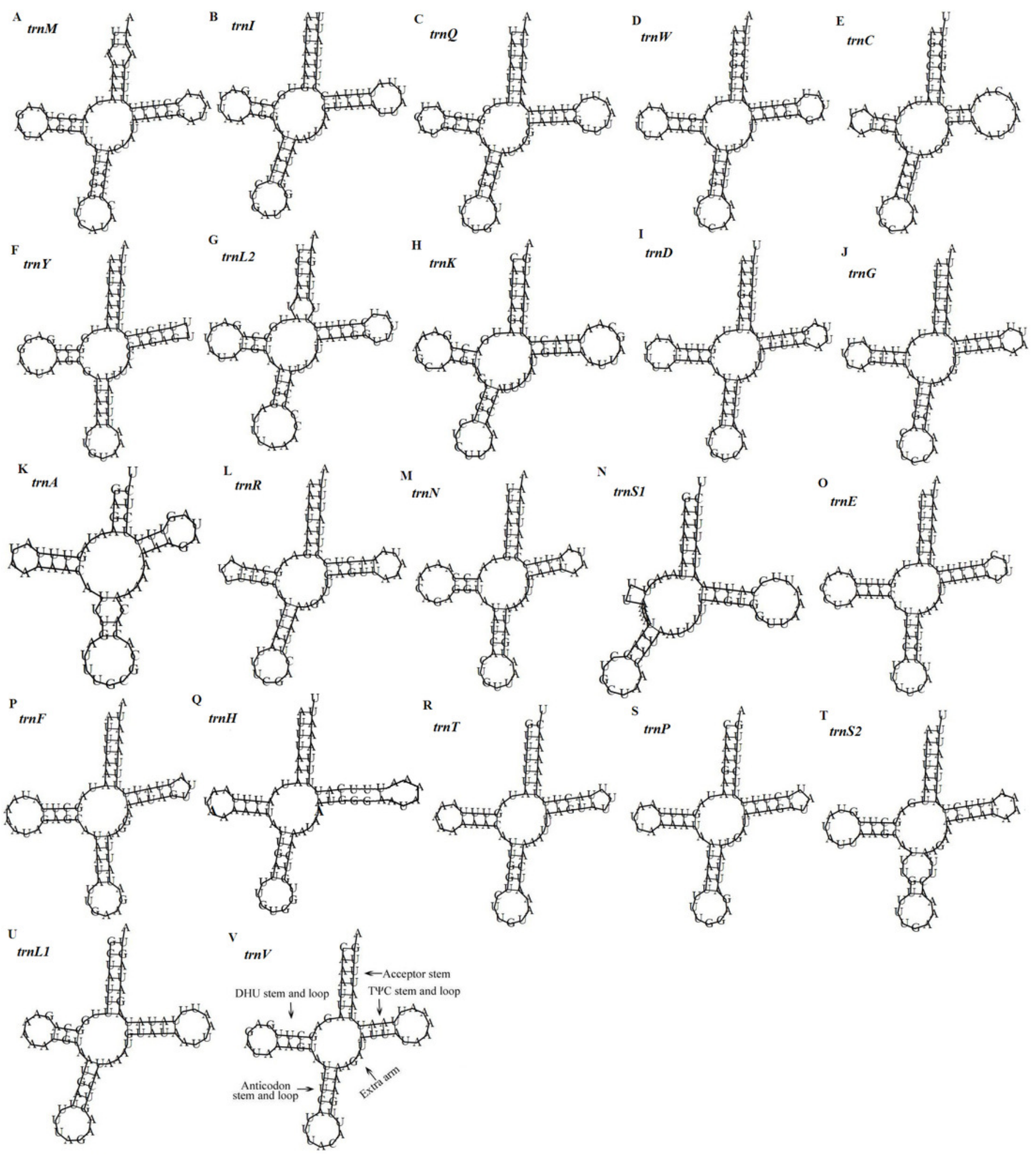




\section{Figure 6}

Features in the intergenic spacer and the $\mathrm{A}+\mathrm{T}$ rich region.

(A) Alignment of the intergenic spacer region between trnS2 and nad1 of several Noctuoidea insects. (B) Features present in the A+T-rich region of $D$. stuposa. The 'ATAGA' motif is shaded. The poly-T stretch is underlined and the poly-A stretch is double underlined. The single microsatellite 'AT' repeat sequence is indicated by dotted underlining. 
A Dysgonia stuposa (Erebidae) Asota plana lacteata (Erebid ae) Vamuna virilis (Erebidae) Gynaephora minora (Erebidae) Risoba prominens (Nolide) Ochrogaster lunifer (Notod ontid ae) Agrotis ipsilon (Noctuidae)

\author{
ATACTAAAAATAATCAACAAAA \\ ATACTAAAAATAATCAATAA \\ ATACTAAAAATAATTAATT \\ TATACTAAAAAAAAT TATACAATTA \\ ATACTAAAAATAATTAA \\ ATACTAAAAATAATTAA \\ ATACTAAAAAAAATTAAA
}

\section{B}

rrnS-15,315-TTTATAT GCACAATTTCTCACATAGATTTTTTTTT TTTTTTTTTTTATATTTAAATATTTATTATATAATATTATTTTAT ATTAAAATATTTAATATAATTAT TAAATATTAAATAATTTCTTT TTCTTTTTTCTTCATACTATTCATATTGAAACCTAATTTGGAA ATTAAACAATTACAATTCTTAAAAATTACAATATATTAATATAA TTAATAATAATTTTTCTTAATAAGTTAATGAATTATAAATATTT TAATTTAT TTAAAAATTTAATATATATATATAAATATTAATTTTA TAAAAATTTAATATATATATATATATATATAATTTTAAAGAAAAT TATTATTTAATTATGTATTTAAACCATTTTTAATAATAATGCAT AT AAATAAAAAAAAATA-15,721-trnM 


\section{Figure 7}

The phylogenetic relationships within Noctuoidea.

(A) Tree showing the phylogenetic relationships among 43 species, constructed using Maximum Likelihood with 1000 bootstrap replicates. (B) Tree constructed using Bayesian Inference (BI) MCMC consensus tree, with posterior probabilities shown at nodes. Bombyx mori ( AY048187 ) and Antheraea pernyi ( AY242996) were used as outgroups. 

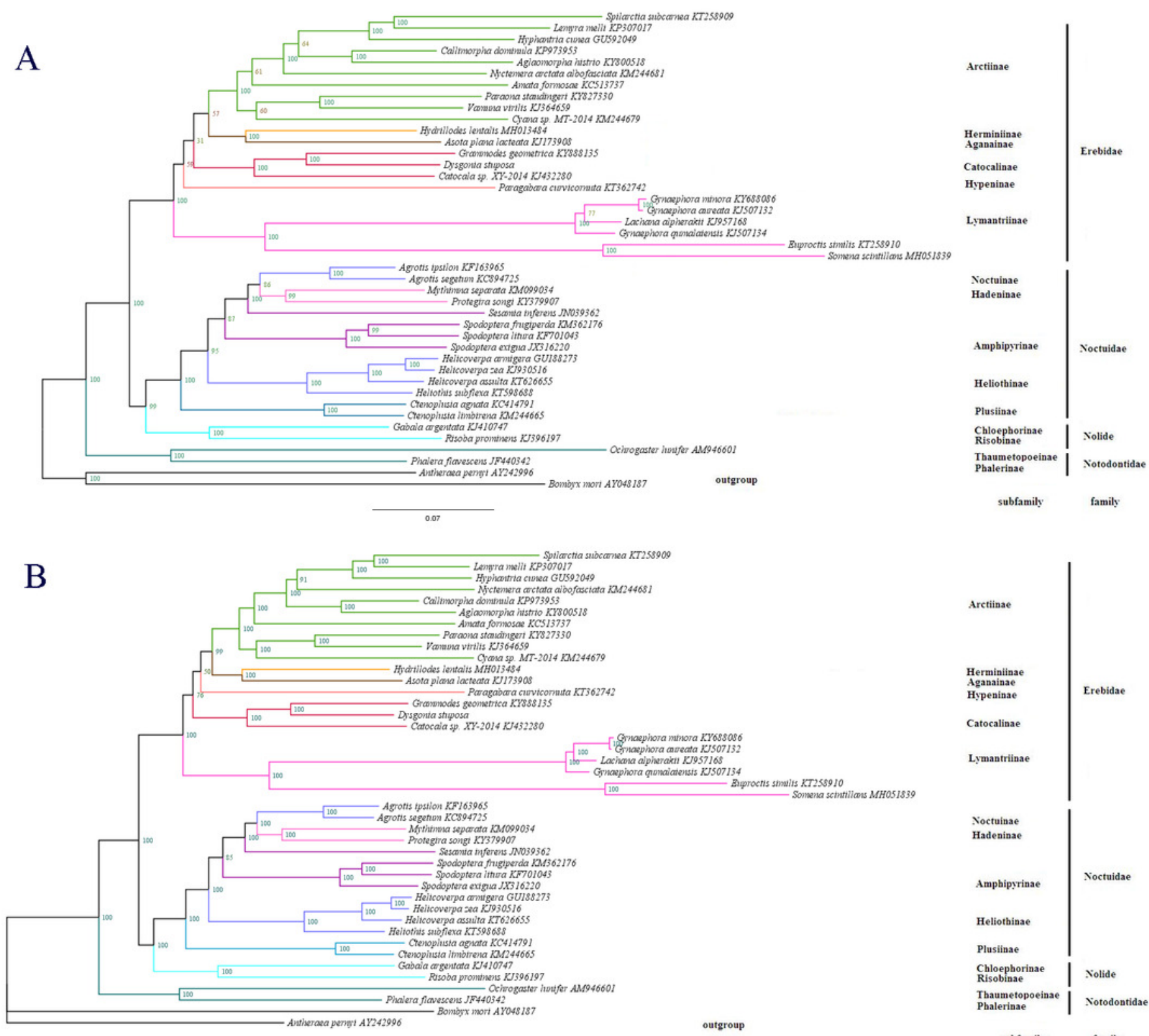

Aretiinae

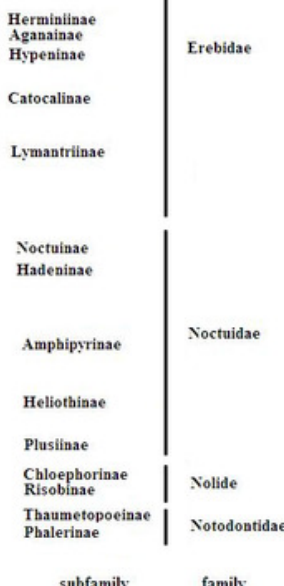

